\title{
Editorial
}

\section{AO Craniomaxillofacial Surgery (AO CMF): A World of Opportunities}

\author{
Dinesh Kadam ${ }^{1}$ \\ ${ }^{1}$ Department of Plastic and Reconstructive Surgery, A J Institute of \\ Medical Sciences and A J Hospital and Research Centre, Mangalore, \\ Karnataka, India
}

Indian J Plast Surg:2020;53:317-320

The specialty of plastic surgery encompassing several subspecialties requires comprehensive training in each. For effective in-depth teaching and learning, resources beyond the prescribed curriculum are desirable and often essential. With the digital revolution and easy accessibility, several learning modules such as online continued medical education (CME), technical videos, case discussions, and literature on current practices are amply available. These resources are based on individual surgeon's experience, podcast/webcast proceedings of societies' meetings, or topic-based interactive sessions of experts. No platform provides everything that a trainee needs for learning, a practicing surgeon to become better, an opportunity for a researcher, interdisciplinary global networking for clinicians, an international audience for a yearning educator, and an eventual benefit for patient care. One such platform, perhaps underrepresented and underutilized by the APSI members, is AO-Craniomaxillofacial Surgery (AO $\mathrm{CMF}$ ). For maxillofacial surgery, there cannot be a better organization than the AO CMF, offering so comprehensively, consistently, and uniformly on a global scale. Interdisciplinary specialists from Plastic surgery, Maxillofacial surgery, ENT, Head \& Neck surgery, Ophthalmology, and Neurosurgery are part of this worldwide community. As a nonprofit organization, the prime objective is to improve patient care through education, innovation, and opportunities for surgeons. It is a gateway for younger surgeons to pursue fulfilling careers and becoming leaders within the $\mathrm{AO} C \mathrm{CMF}$ community.

AO CMF is a part of the AO Foundation ${ }^{1}$ with four other divisions-AO Trauma, AO Spine, AO Vet, and AO Reconstruction. Founded 60 years ago by 13 visionary Swiss surgeons, the Association of Osteosynthesis (AO-Arbeitsgemeinschaft für Osteosynthesefragen) has deeply impacted patient care, clinical investigation, education, and research worldwide ${ }^{2}$ (-Fig. 1). Since its inception, more than 660,000 surgeons and related personnel have participated in AO courses, to date, in over 124 countries. A global community of 215,000 individuals, AO annually conducts over 830 educational events, with a participation of 9000 faculties and 58,000 attendees. ${ }^{1}$

With the AO headquarters in Davos, the organization has five regional divisions, including the Asia Pacific region. Prof. Gopalakrishnan of Dharwad, India, will be the new Head of AO Asia Pacific. There are currently 3400 members worldwide conducting over 120 events annually, providing an opportunity for learning and networking for over 7000 participants. ${ }^{3}$ Out of 247 from India, 22 are plastic surgeons as members and faculty (-Table $\mathbf{1}$ ), among other specialties ( - Fig. 2).

The AO CMF is a continuously evolving organization with innovative research, techniques, and education. There is a world of opportunities and benefits of becoming AO CMF members with access to events, educational material, publications, and the prospect to be a faculty. It is worthwhile to note some of the unique features of $\mathrm{AO} \mathrm{CMF}^{3}$ for the benefit of trainees and practicing surgeons:

AOCMF courses: Regularly held maxillofacial trauma (MFT) courses cover the basics of trauma management with didactic lectures, small group discussions, and hands-on practical exercises on osteosynthesis ( - Fig. 3). Specifically designed for trainees and practicing surgeons, the principle course structure and curriculum have evolved uniformly throughout the world, with a specific regional and national faculty involvement. Further, there are several advanced courses on specific clinical conditions held across the globe. Every AO course and event is monitored by the Davos headquarters and continuously revised and adopted. There is intense involvement from the faculty and participants with precourse assessment, postcourse briefing, deliberations, and feedback on each topic and the presenter.

\author{
Address for correspondence \\ Dinesh Kadam MS, DNB, MCh, Professor \\ and Head, Department of Plastic and \\ Reconstructive Surgery, A Institute of \\ Medical Sciences and A J Hospital and \\ Research Centre, Mangalore, Karnataka \\ 575004, India (e-mail: drkadam@yahoo.co.in).
}

DOI https://doi.org/ 10.1055/s-0040-1722805 ISSN 0970-0358.

\footnotetext{
(C) 2020. Association of Plastic Surgeons of India.

This is an open access article published by Thieme under the terms of the Creative Commons Attribution-NonDerivative-NonCommercial-License, permitting copying and reproduction so long as the original work is given appropriate credit. Contents may not be used for commercial purposes, or adapted, remixed, transformed or built upon. (https://creativecommons.org/licenses/by-nc-nd/4.0/).

Thieme Medical and Scientific Publishers Pvt. Ltd. A-12, 2nd Floor, Sector 2, Noida-201301 UP, India
} 


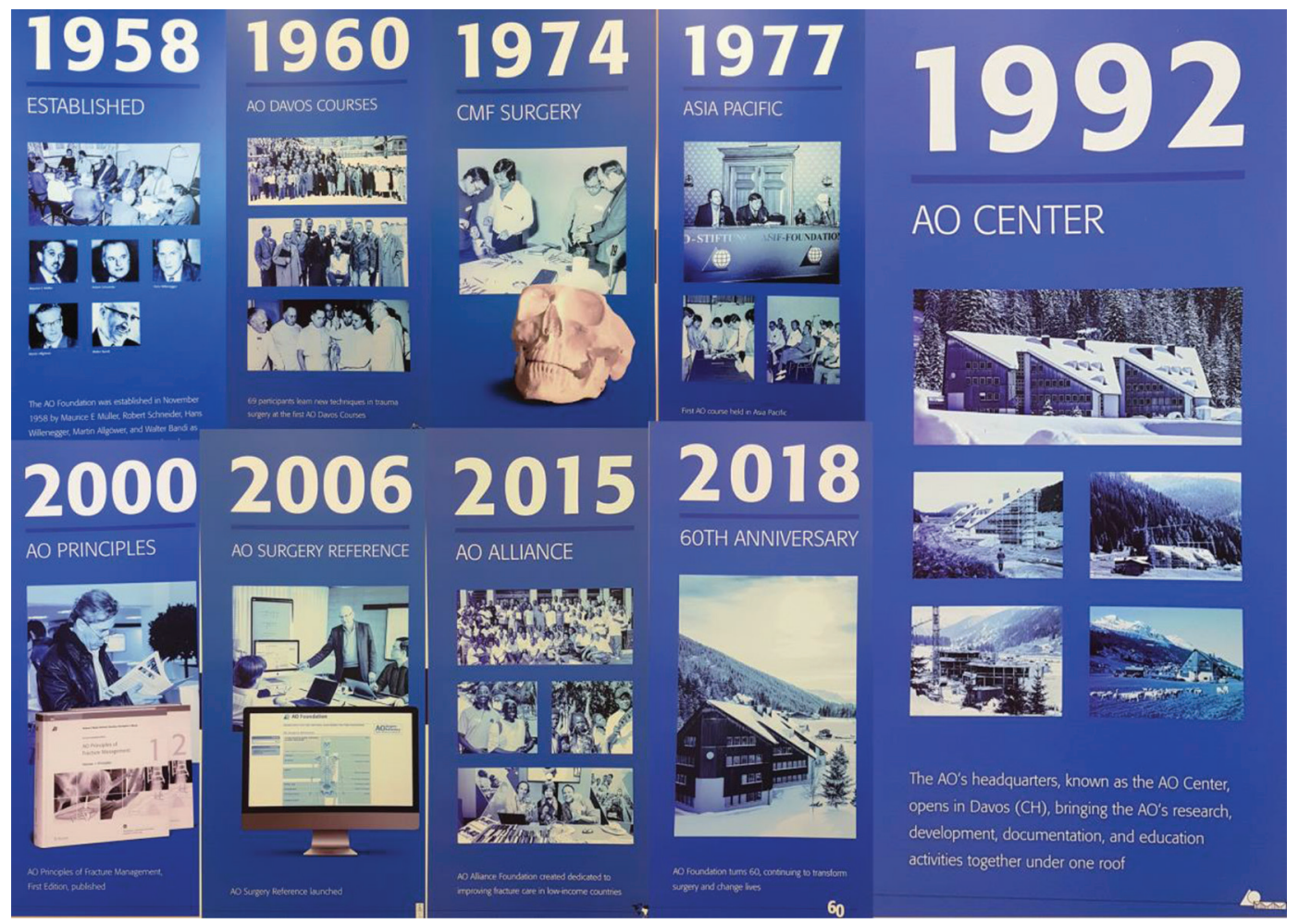

Fig. 1 The evolution of AO Foundation-Assimilation of displayed information at Davos center.

AO Surgery reference: It is an innovative digital tool for various craniofacial surgery described in an easy step-by-step manner which acts as a portal of reference for surgical planning. The CMF module includes skeletal trauma, deformities, orthognathic surgery, reconstruction, nose reconstruction, facial nerve paralysis, and so on. Developed based on AO principles by the expertise, several surgical procedures for different facial regions with high-quality images and videos are easily accessible.

$A O$ Video and visual media: Videos on surgical procedures, practical exercises, including live interactive webinars and lectures, and expert case discussions on a wide range of topics are made available. These are produced in-house by a professional team from initial concept and meticulous development to final delivery. The Davos center has a dedicated clinical division for live streaming of e-lectures and educational events ( - Fig. 4).

Publication: AOMCF has published Craniomaxillofacial Trauma \& reconstruction (CMTR) journal for the past 13 years along with an open-access publication CMTR Open. Members get access to CMTR journal and free submissions to CMTR Open along with publications of Science Direct. AOCMF manuals are available for surgeons.

AO CMF Fellowships Program: AO CMF supports yearly 65 clinical fellowships of 4 to 6 weeks at designated centers worldwide, covering the entire scope of CMF surgical procedures. This is particularly valuable to young surgeons to meet and work with the leading experts.

AO Faculty development program: The faculty development programs help practicing surgeons develop their skills and become faculty and educators. From national to regional and international levels, the "faculty pathway" is based on selection
Table 1 AO CMF members and faculty-India

\begin{tabular}{|l|l|l|}
\hline Specialty & $\begin{array}{l}\text { AO CMF } \\
\text { members }\end{array}$ & $\begin{array}{l}\text { AO CMF } \\
\text { faculty }\end{array}$ \\
\hline $\begin{array}{l}\text { Oral \& maxillofacial } \\
\text { surgery }\end{array}$ & 160 & 25 \\
\hline Plastic surgery & 22 & 10 \\
\hline ENT & 2 & - \\
\hline Ophthalmology & 2 & 2 \\
\hline Head and neck surgery & - & 1 \\
\hline Others $^{\mathrm{a}}$ & 61 & - \\
\hline Total $^{\mathrm{b}}$ & 247 & 38 \\
\hline
\end{tabular}

${ }^{\mathrm{b}}$ Data as of December 2020. ${ }^{\mathrm{a}}$ Others include incomplete information on a specialty.

criteria, performance assessment, and expertise in their field. Further, each faculty is continuously evaluated and tracked for his or her performance by the regional headquarters Thus, the faculty are highly motivated and dedicated experts who teach a safe and standard practice of $\mathrm{AO}$ principles.

Research: The organization provides research grants for clinical priority programs and several preclinical and clinical research projects. AO CMF's Research and Development (R\&D) and AO clinical investigation division (AO CID) activities aim to produce new findings and develop them into practice to impact CMF injuries' clinical care.

AO CMF classification system: The AO CMF has recently launched the first comprehensive classification system for CMF fractures. This multiplanar radiographic image-based AO CMF trauma classification system is constantly evolving and has entered clinical application. ${ }^{4}$ 


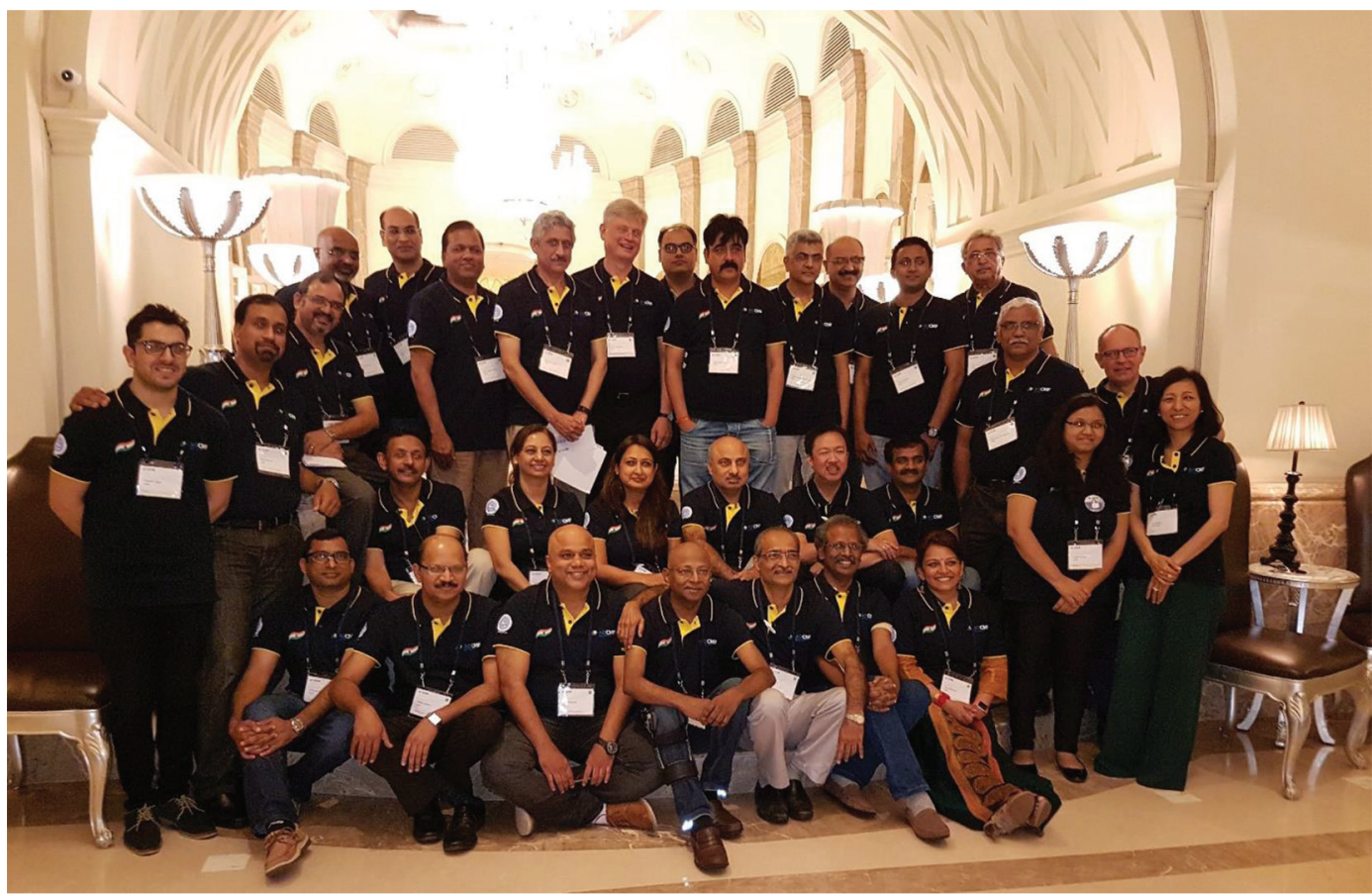

Fig. 2 AO CMF faculty of India at a meeting in Mumbai, 2017.

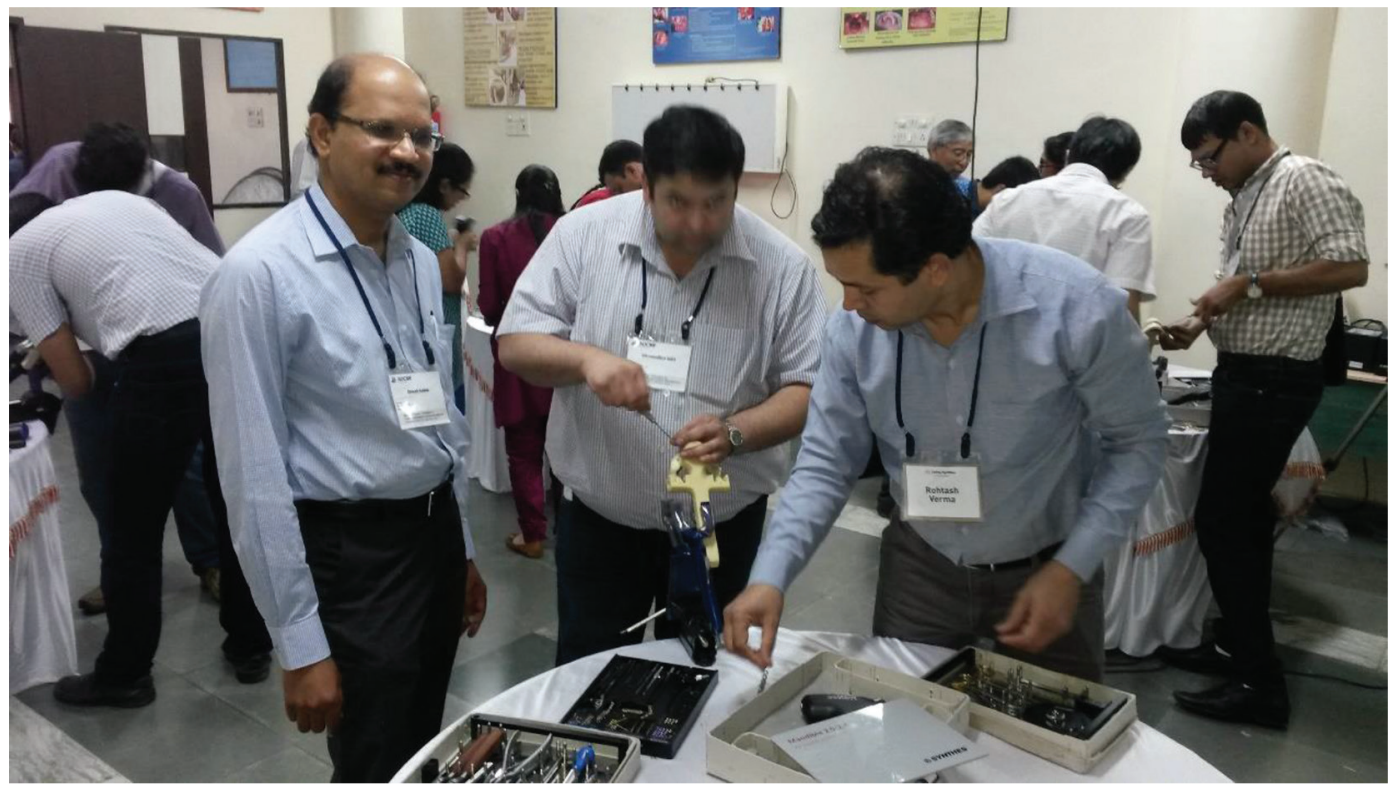

Fig. 3 Hands-on practical exercise session at MFT course in India

AO Innovation Translation Center (AO ITC):An AO innovation hub launched in March 2020 integrates other AO divisions-AO Technical Commission (AO TC), Technology Transfer, Clinical Operations, and Clinical Science units.

AO Program for Education and Excellence in Research (AO PEER): The recently launched AO PEER provides a collection of clinical research resources, reference documents, and learning opportunities. They are designed by the task force specifically for practicing clinicians to conduct clinical research and publications. The program is supported by faculty of other
AO divisions, AO Education Institute, and the AO Innovation Translation Center.

A nonprofit organization: The AO remains a nonprofit organization, and the funding comes through membership (CHF 100/year) and industrial partners who support the logistics without any conflicts of interest. The organization is democratic, and each representative, either national, regional, trustee, or the AO President, is elected by the eligible voting members.

The CME, evidence-based practice, and collaborative research remain the cornerstones of best practices for patient 


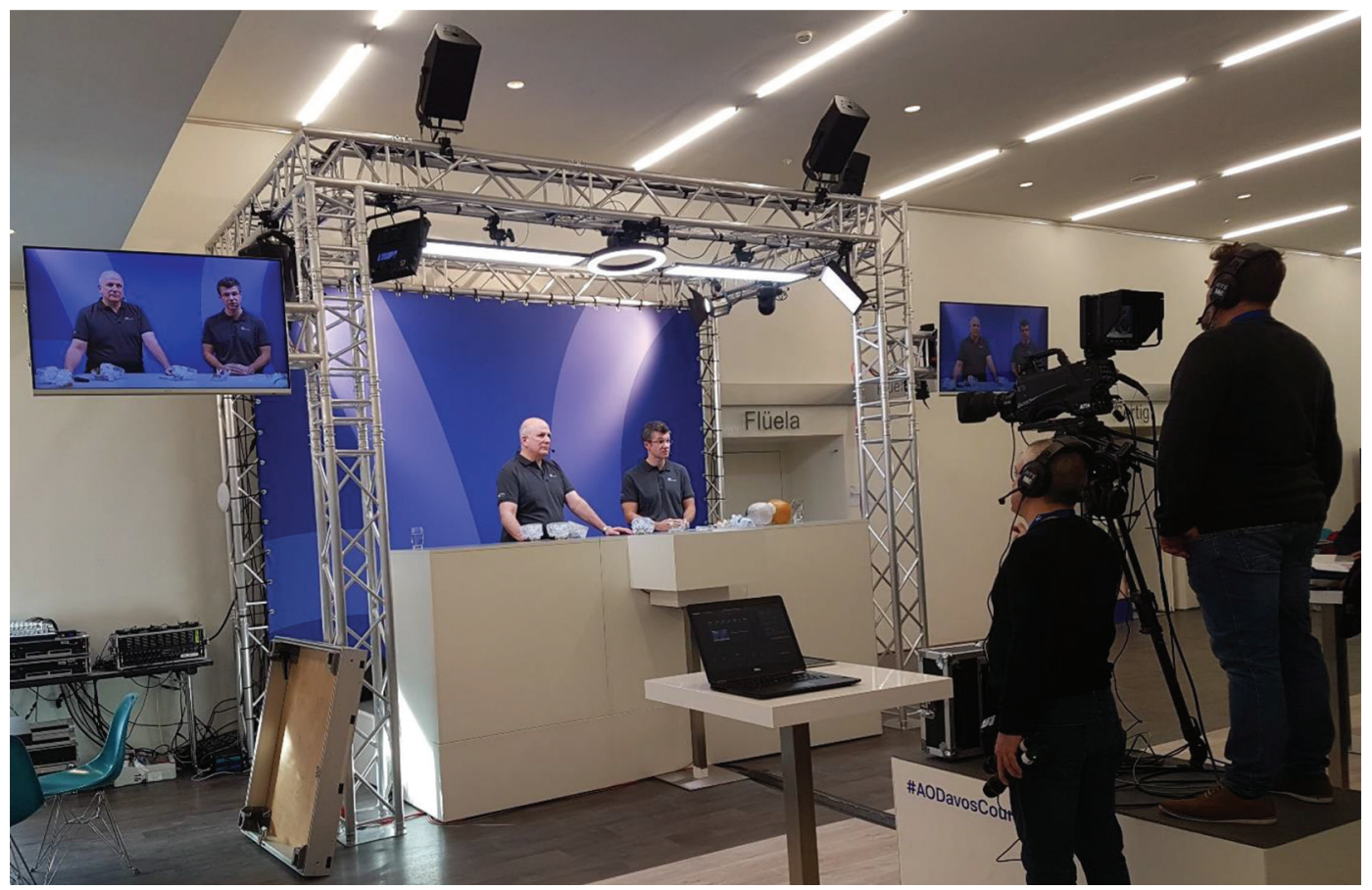

Fig. 4 Live webinar in progress at AO Centre, Davos, December 2019.

care and enhance the surgeon's practice capabilities. AO CMF has brought together clinicians globally, infused high standards of practice across specialties, and impacted the standard of patient care. It is an excellent opportunity for members of APSI to consider joining this wonderful community that fosters interactive opportunities, interspecialty relationships, and positive career progression: to be a better surgeon, a teacher, and a researcher.

\section{Declaration}

The author is a regional faculty of AO CMF and AO PEER

\section{Conflicts of Interest}

None declared.

\section{References}

1 AO. Available at: https://www.aofoundation.org/. Accessed December 9, 2020

2 Joeris A, Höglinger M, Meier F, et al. The impact of the AO Foundation on fracture care: An evaluation of 60 years AO Foundation. Injury 2019;50(11):1868-1875

3 AO CMF. Available at: https://aocmf.aofoundation.org/. Accessed December 11, 2020

4 Mittermiller PA, Bidwell SS, Thieringer FM, et al; and the AO Trauma Classification Study Group. The comprehensive AO CMF classification system for mandibular fractures: a multicenter validation study. Craniomaxillofac Trauma Reconstr 2019;12(4):254-265 